\title{
GERMINAÇÃO DE SEMENTES DE Vochysia bifalcata EM DIFERENTES SUBSTRATOS E TEMPERATURAS
}

\author{
Helena Cristina Rickli ${ }^{1}$, Antonio Carlos Nogueira ${ }^{2}$, Henrique Soares Koehler ${ }^{3}$, \\ Katia Christina Zuffellato-Ribas ${ }^{4}$
}

1Bióloga, Doutoranda em Agronomia, Produção Vegetal, UFPR, Curitiba, PR, Brasil - crisnenah @ gmail.com

${ }^{2}$ Eng. Florestal, Dr., Depto. de Ciências Florestais, UFPR, Curitiba, PR, Brasil - nogueira@ufpr.br

${ }^{3}$ Eng. Florestal, Dr., Depto. de Fitotecnia e Fitossanitarismo, UFPR, Curitiba, PR, Brasil - koehler@ufpr.br

${ }^{4}$ Bióloga, Dr ${ }^{\mathrm{a}}$., Depto. de Botânica, UFPR, Curitiba, PR, Brasil - kazu@ufpr.br

Recebido para publicação: 06/10/2013 - Aceito para publicação: 20/03/2014

\begin{abstract}
Resumo
Guaricica (Vochysia bifalcata) é uma espécie arbórea nativa do Brasil, presente na vegetação secundária da Floresta Ombrófila Densa dos estados do Paraná, Santa Catarina, São Paulo, Rio de Janeiro e Minas Gerais, sendo de grande importância na regeneração de áreas degradadas e para fins madeireiros. Este estudo teve por objetivo avaliar os efeitos de diferentes temperaturas (20, 25 e $30{ }^{\circ} \mathrm{C}$ ) e substratos (rolo de papel, papel mata-borrão e vermiculita) na germinação de sementes de Vochysia bifalcata, as quais foram mantidas em germinadores sob luz constante. Foram realizadas avaliações diárias até o $20^{\circ}$ dia após a semeadura, analisando-se as seguintes variáveis porcentagem de germinação, índice de velocidade de germinação, tempo médio de germinação e índice de sincronização. A temperatura de $25{ }^{\circ} \mathrm{C}$, nos substratos papel mata-borrão e vermiculita apresentaram a maior germinação (70 e 73\%, respectivamente) e maior índice de velocidade de germinação, porém com menor sincronismo. Assim, para o teste de germinação de guaricica, é recomendado o uso dos substratos papel mata-borrão ou vermiculita na temperatura de $25^{\circ} \mathrm{C}$.

Palavras-chave: Vochysiaceae; guaricica; índice de sincronização; índice de velocidade de germinação.
\end{abstract}

\begin{abstract}
Germination of Vochysia bifalcata under different substrates and temperatures. Guaricica (Vochysia bifalcata) is a native Brazilian tree species, present in the secondary vegetation of the Ombrophilous Dense Forest in the States of Paraná, Santa Catarina, São Paulo, Rio de Janeiro, and Minas Gerais. It is of great importance in degraded areas regeneration and for timber production. This research aimed to evaluate the effects of different temperatures $\left(20,25\right.$ and $\left.30{ }^{\circ} \mathrm{C}\right)$ and substrates (paper roll, blotting paper and vermiculite) during the germination of Vochysia bifalcata seeds. We conducted germination tests inside germination chambers under constant illumination. Until the 20th day after the installation, daily evaluations analyzed the following variables: germination percentage, germination speed index, average germination time, and synchronization index. The temperature of $25{ }^{\circ} \mathrm{C}$ in blotting paper and vermiculite substrate presented the highest germination (70 and $73 \%$, respectively) and highest germination speed index, but with less synchronism. Therefore, it recommends use of blotting paper and vermiculite as substrates in a temperature of $25^{\circ} \mathrm{C}$ for the Vochysia bifalcata germination test.

Keywords: Vochysiaceae; guaricica; index synchronization; germination speed index
\end{abstract}

\section{INTRODUÇÃO}

O desenvolvimento de técnicas para a produção de mudas de espécies nativas em viveiros tem sido uma das etapas mais importantes dos programas de recuperação ambiental. Para tanto, análises físicas e fisiológicas de sementes são necessárias para o conhecimento das condições ideais de germinação, tornando-se primordial para o sucesso da produção de mudas (BORGES et al., 2007; REGO et al., 2009). 
A produção de mudas de espécies florestais nativas é limitada, visto que da maioria ainda não se conhece a biologia de suas sementes e plântulas, dificultando o estabelecimento de parâmetros para o teste de germinação (NOVEMBRE et al., 2007). Poucas recomendações são encontradas para análises de sementes florestais, principalmente nativas (ANDRADE et al., 2000), fator esse apontado nas Regras de Análises de Sementes (RAS) (BRASIL, 2009).

Para a produção de mudas, é extremamente necessário o conhecimento de condições que proporcionem uma germinação rápida e um desenvolvimento homogêneo das plântulas. Com isso, as mudas se desenvolvem rapidamente, com um povoamento uniforme, que proporciona um menor trabalho aos viveiristas (PACHECO et al., 2006). Segundo Carvalho e Nakagawa (1988), o processo germinativo varia para cada espécie, sendo influenciado por fatores extrínsecos às sementes, como disponibilidade de água e temperatura. Assim, são de grande importância testes de germinação que estabeleçam a temperatura e o substrato ótimo para determinada espécie.

A germinação só ocorre dentro de determinados limites de temperatura, sendo ideal aquela que proporciona maior potencial de germinação em menor tempo (CARVALHO; NAKAGAWA, 1988). Entre as diversas espécies existentes, ocorre grande variação quanto à temperatura ideal de germinação de suas sementes, sendo que, geralmente, a faixa ideal situa-se entre as temperaturas encontradas na época propícia à emergência natural na região de origem da espécie (ANDRADE et al., 2000). Para a maioria das espécies tropicais e subtropicais, as temperaturas entre 20 e $30{ }^{\circ} \mathrm{C}$ têm sido as mais adequadas para a germinação (SILVA; AGUIAR, 1998).

O fornecimento de água é uma condição essencial para que a semente inicie a germinação e se desenvolva, variando a quantidade para cada tipo de substrato, de acordo com suas propriedades físicas. Este deve ser mantido suficientemente úmido durante a realização do teste, disponibilizando a quantidade necessária de água para a germinação e evitando a formação de película de água sobre as sementes, a qual impede a penetração de oxigênio e contribui para a proliferação de patógenos (BRASIL, 2009).

A espécie em estudo, Vochysia bifalcata Warm., conhecida popularmente como guaricica ou paude-vinho, pertencente à família Vochysiaceae. É uma planta de hábito arbóreo, podendo alcançar aproximadamente $25 \mathrm{~m}$ de altura e $100 \mathrm{~cm}$ de diâmetro à altura do peito (DAP), possuindo copa densa perenifólia. É uma espécie secundária inicial que forma agrupamentos densos na fase de capoeira, sendo dominante até a fase de capoeirão. A espécie encontra-se distribuída de forma natural na Floresta Ombrófila Densa nos estados do Paraná, Santa Catarina, Rio de Janeiro, São Paulo e Minas Gerais. É recomendada para revegetação e recuperação de áreas degradadas, além do seu potencial madeireiro (NEGRELLE et al., 2007; CARVALHO, 2003). No entanto, o desconhecimento das condições necessárias para a germinação das sementes e desenvolvimento de plântulas de Vochysia bifalcata em viveiros acarreta dificuldades na produção de suas mudas (CARPANEZZI; CARPANEZZI, 2006), existindo apenas a referência de Carvalho (2003), que relata que a germinação da espécie é baixa e irregular (22 a 50\%), com início entre 20 a 50 dias após a semeadura, sem indicar informações sobre a condução do teste.

Diante da importância de estudos da espécie, o presente trabalho teve como objetivo avaliar o comportamento germinativo de sementes de Vochysia bifalcata em diferentes substratos e temperaturas.

\section{MATERIAL E MÉTODOS}

A coleta dos frutos de Vochysia bifalcata foi realizada na Reserva Natural do Morro da Mina, pertencente à Sociedade de Pesquisa em Vida Selvagem e Educação Ambiental (SPVS), no município de Antonina, PR, entre os paralelos $25^{\circ} 21^{\prime}$ e $25^{\circ} 25^{\prime} \mathrm{S}$ e $48^{\circ} 46^{\prime} \mathrm{e} 48^{\circ} 51^{\prime} \mathrm{W}$, altitude aproximada de $23 \mathrm{~m}$, solo do tipo Cambissolo Háplico Tb distrófico. Segundo a classificação de Köppen, o clima da região é do tipo $\mathrm{Cfa}$, isto é, clima caracterizado como subtropical com temperatura média do mês mais frio inferior a $18^{\circ} \mathrm{C}$ (mesotérmico) e temperatura média do mês mais quente acima de $22^{\circ} \mathrm{C}$, com verões quentes, geadas pouco frequentes e tendência de concentração de chuvas nos meses de verão, contudo sem estação seca definida.

Em dezembro de 2010, foram selecionadas quatro plantas-matrizes adultas, distantes entre si, para coleta de frutos, os quais foram levados ao Laboratório de Sementes Florestais do Departamento de Ciências Florestais da Universidade Federal do Paraná, em Curitiba, PR, para realização dos experimentos. Os frutos foram submetidos a secagem natural à temperatura ambiente por 72 horas, para completa abertura e liberação das sementes. Primeiramente, foi realizado o processo de seleção manual das sementes, para a remoção de sementes imaturas, infectadas, sem ala, de menor tamanho e material inerte, para obtenção de sementes puras de Vochysia bifalcata, formando assim quatro lotes, de acordo com as matrizes. Posteriormente, as sementes puras provenientes dos quatro lotes foram misturadas, 
compondo um único lote, passando pelo processo de homogeneização manual, com a finalidade de se obterem amostras mais representativas. As sementes foram armazenadas em sacos de papel, em câmara fria $\left(5 \pm 1{ }^{\circ} \mathrm{C} ; 85 \%\right.$ UR) por cinco dias, para, em seguida, proceder-se à realização dos testes.

\section{Análises físicas}

Com base nas Regras de Análise de Sementes (BRASIL, 2009), o peso de mil sementes foi obtido utilizando-se oito repetições de 100 sementes com ala de Vochyisia bifalcata, com o uso de balança analítica com precisão de $0,001 \mathrm{~g}$. Calculou-se a média, o coeficiente de variação e o número de sementes por quilo. A maioria das análises de caracterização física de sementes varia em função do teor de água contido na partícula. Assim, foi determinado o grau de umidade das sementes, por meio do método de estufa $105^{\circ} \mathrm{C}$ (BRASIL, 2009), utilizando-se quatro amostras de 25 sementes com ala.

\section{Teste de germinação}

O teste de germinação foi conduzido em câmaras de germinação do tipo Biomatic, para o estudo dos substratos e das temperaturas. Foram utilizados três diferentes tipos de substratos (rolo de papel toalha, papel mata-borrão e vermiculita de granulometria fina) e três condições de temperaturas $(20,25$ e $\left.30{ }^{\circ} \mathrm{C}\right)$ sob luz constante.

Previamente, os substratos foram esterilizados em estufa a $105 \pm 3{ }^{\circ} \mathrm{C}$ por 24 horas. O rolo de papel toalha e o papel mata-borrão foram umedecidos adicionando-se 2,5 vezes o peso do papel seco em quantidade de água destilada (BRASIL, 2009). O substrato vermiculita granulometria fina foi previamente umedecido na proporção de $20 \mathrm{~g}$ de substrato em $50 \mathrm{~mL}$ de água destilada.

As sementes com ala foram colocadas para germinar sobre uma folha de papel mata-borrão e vermiculita em caixas plásticas transparentes $(11,0 \times 11,0 \times 3,0 \mathrm{~cm})$, enquanto que para o rolo de papel foram utilizadas três folhas de papel toalha, sendo as sementes dispostas sobre duas folhas e recobertas por outra folha, para posterior confecção dos rolos.

As avaliações ocorreram diariamente, sendo iniciadas no primeiro dia após a instalação do experimento e encerradas com a avaliação final no $20^{\circ}$ dia, quando sementes não germinavam mais. Considerou-se semente germinada aquela que apresentava protrusão da raiz primária com, no mínimo, $2 \mathrm{~mm}$ de comprimento.

As variáveis analisadas foram: porcentagem de germinação $(\% \mathrm{G})$; índice de velocidade de germinação (IVG), segundo Maguire (1962); tempo médio de germinação $(\bar{t})$, segundo Labouriau (1983); índice de sincronização, segundo Labouriau e Agudo (1987); e a porcentagem de mortalidade das sementes, sendo consideradas sementes mortas aquelas que não germinaram e apresentavam deterioração por fungos e bactérias no momento da avaliação.

O delineamento experimental utilizado foi inteiramente casualizado, em arranjo fatorial de $3 \times 3$ (três substratos x três temperaturas), com dez repetições de 20 sementes por unidade experimental. As variáveis, cujas variâncias se mostraram homogêneas pelo teste de Bartlett, foram submetidas à análise de variância, e as que apresentaram diferenças significativas pelo teste de $\mathrm{F}$ tiveram suas médias comparadas pelo teste de Tukey ao nível de 5\% de probabilidade.

\section{RESULTADOS E DISCUSSÃO}

Para as análises físicas das sementes de Vochysia bifalcata, foram obtidos grau de umidade das sementes de $11,8 \%($ C.V. $=0,75 \%), 94,8 \mathrm{~g}(\mathrm{C} . \mathrm{V} .=1,7 \%)$, para o peso de mil sementes e 10.551 sementes por quilo. $\mathrm{O}$ número de sementes por quilo apresentado no presente trabalho encontra-se abaixo da quantidade citada por Lorenzi (1998). Esse autor relata que para cada quilo existem aproximadamente 23.500 sementes, contudo ele não mencionou o grau de umidade dessas sementes, o que pode ter ocasionado esse maior número de sementes, como também pode estar relacionado à origem das sementes ou à presença de ala nas sementes no momento da realização do teste.

Foi observada interação entre os fatores estudados para todas as variáveis analisadas, indicando que a germinação de sementes de Vochysia bifalcata em laboratório depende da temperatura e do tipo de substrato a que são submetidas (Tabela 1). Segundo Figliolia et al. (1993), a interação entre temperatura e substrato é de grande importância, afirmando que a capacidade de retenção de água que cada substrato proporciona às sementes é responsável pelas diferentes respostas até mesmo para a mesma temperatura, o que foi observado no presente trabalho. 
Tabela 1. Resultados da análise de variância para a porcentagem de germinação $(\mathrm{G})$, índice de velocidade de germinação (IVG), tempo médio de germinação $(\bar{t})$ e índice de sincronização de sementes de Vochysia bifalcata, submetidas a temperaturas constantes e diferentes substratos, coletadas em Antonina, PR, 2011.

Table 1. Results of analysis of variance for germination percentage, germination speed index, average germination time and synchronization index of Vochysia bifalcata seeds under constant temperatures and different substrates, collected in Antonina, PR, 2011.

\begin{tabular}{|c|c|c|c|c|c|}
\hline \multirow{2}{*}{ Fontes de variação } & \multirow{2}{*}{ G. L. } & \multicolumn{4}{|c|}{ Quadrado médio } \\
\hline & & $\mathbf{G}$ & IVG $^{1}$ & $\bar{t}^{1}$ & Índice de sincronização ${ }^{1}$ \\
\hline Temperatura (A) & 2 & $48028 * *$ & $18,08^{* *}$ & $468 * *$ & $7,74 * *$ \\
\hline Substrato (B) & 2 & $995^{* *}$ & $1,14^{* *}$ & $2,44^{\mathrm{ns}}$ & $2,85^{* *}$ \\
\hline Interação A x B & 4 & $7076^{* * *}$ & $1,66^{* *}$ & $26,37 * *$ & $3,35 * *$ \\
\hline Erro & 81 & 7505 & 0,07 & 2,8 & 0,23 \\
\hline Total & 89 & & & & \\
\hline C.V. (\%) & & 20,38 & 22,52 & 21,51 & 31,83 \\
\hline $\mathrm{X}^{2}$ & & $19,11^{\mathrm{ns}}$ & $10,23^{\text {ns }}$ & $3,10^{\mathrm{ns}}$ & $14,22^{\text {ns }}$ \\
\hline
\end{tabular}

Tabela 2. Porcentagem de germinação, índice de velocidade de germinação (IVG), tempo médio de germinação $(\bar{t})$ e índice de sincronização de sementes de Vochysia bifalcata submetidas a temperaturas constantes e diferentes substratos, coletadas em Antonina, PR, 2011.

Table 2. Seeds germination percentage, germination speed index, average germination time, synchronization index of Vochysia bifalcata seeds under constant temperatures and different substrates, collected in Antonina, PR, 2011.

\begin{tabular}{|c|c|c|c|}
\hline \multirow{2}{*}{$\begin{array}{l}\text { Temperaturas } \\
\left({ }^{\circ} \mathrm{C}\right)\end{array}$} & \multicolumn{3}{|c|}{ Substratos } \\
\hline & Rolo de papel & Papel mata-borrão & Vermiculita \\
\hline & & \% germinação & \\
\hline 20 & $57 \mathrm{Aa}$ & $59 \mathrm{Ab}$ & $61 \mathrm{Ab}$ \\
\hline 25 & $62 \mathrm{Ba}$ & $70 \mathrm{ABa}$ & $73 \mathrm{Aa}$ \\
\hline \multirow[t]{2}{*}{30} & $37 \mathrm{Ab}$ & $3 \mathrm{Bc}$ & $6 \mathrm{Bc}$ \\
\hline & & IVG & \\
\hline 20 & $1,11 \mathrm{Ab}$ & $0,92 \mathrm{Ab}$ & $0,99 \mathrm{Ab}$ \\
\hline 25 & $1,86 \mathrm{Ba}$ & 2,16 Aa & $2,05 \mathrm{ABa}$ \\
\hline \multirow[t]{2}{*}{30} & $1,24 \mathrm{Ab}$ & $0,08 \mathrm{Bc}$ & $0,18 \mathrm{Bc}$ \\
\hline & & $\bar{t}$ & \\
\hline 20 & $10,5 \mathrm{Ba}$ & $13 \mathrm{Aa}$ & $12,6 \mathrm{Aa}$ \\
\hline 25 & $7,1 \mathrm{Ab}$ & $6,8 \mathrm{Ab}$ & $7,2 \mathrm{Ab}$ \\
\hline \multirow[t]{2}{*}{30} & $6,3 \mathrm{Ab}$ & $2,6 \mathrm{Bc}$ & $3,9 \mathrm{Bc}$ \\
\hline & & Índice de sincronizaçã & \\
\hline 20 & $1,6018 \mathrm{Aa}$ & $1,8204 \mathrm{Aa}$ & $1,9139 \mathrm{Aa}$ \\
\hline 25 & $2,0122 \mathrm{Aa}$ & $1,9421 \mathrm{Aa}$ & $1,5860 \mathrm{Aa}$ \\
\hline 30 & $2,0126 \mathrm{Aa}$ & $0,3182 \mathrm{Bb}$ & $0,4739 \mathrm{Bb}$ \\
\hline
\end{tabular}

Médias seguidas de mesma letra maiúscula na linha e da mesma letra minúscula na coluna não diferem entre si ao nível de $1 \%$ de probabilidade pelo teste de Tukey.

A germinação de Vochysia bifalcata foi beneficiada pela temperatura de $25{ }^{\circ} \mathrm{C}$, com exceção do substrato rolo de papel (Tabela 2). A combinação dos substratos mata-borrão e vermiculita à temperatura de $25{ }^{\circ} \mathrm{C}$ mostrou-se eficiente, com médias de 70 e $73 \%$ de germinação, respectivamente, sendo que o rolo de papel diferiu significativamente apenas do mata-borrão. O presente resultado contradiz a afirmação de Carvalho (2003) de que a germinação das sementes de Vochysia bifalcata é baixa e irregular, com médias entre 22 e $50 \%$, com as diferenças dos resultados podendo estar relacionadas a procedência, potencial fisiológico, armazenamento das sementes e condições experimentais para a condução do teste. A temperatura de $25{ }^{\circ} \mathrm{C}$ também foi considerada como a mais eficiente para promover a germinação em outras espécies do gênero, como Vochysia haenkiana Mart. e Vochysia tucanorum Mart. 
(SILVA et al., 2000; BARBOSA et al., 1999), enquadrando-se na recomendação para a maioria das espécies florestais tropicais, para as quais a temperatura constante de $25{ }^{\circ} \mathrm{C}$ encontra-se na faixa ótima para germinação (RODRIGUES et al., 2008).

Observou-se que todas as sementes que não germinaram apresentaram-se totalmente deterioradas por fungos e bactérias durante a avaliação, sendo assim consideradas mortas, o que justifica a menor germinação na temperatura de $30{ }^{\circ} \mathrm{C}$ nos substratos mata-borrão e vermiculita $(97$ e $94 \%$, respectivamente). Foi possível constatar o fato de que as sementes que não germinaram nessa temperatura tiveram um processo de deterioração acelerado, com lixiviação do conteúdo celular, criando um ambiente propício para o desenvolvimento de micro-organismos (Figura 1). O mesmo foi observado por Rego et al. (2009), em que a germinação de sementes de Blepharocalyx salicifolius (H.B.K.) Berg. foi prejudicada em temperaturas acima de $30^{\circ} \mathrm{C}$.

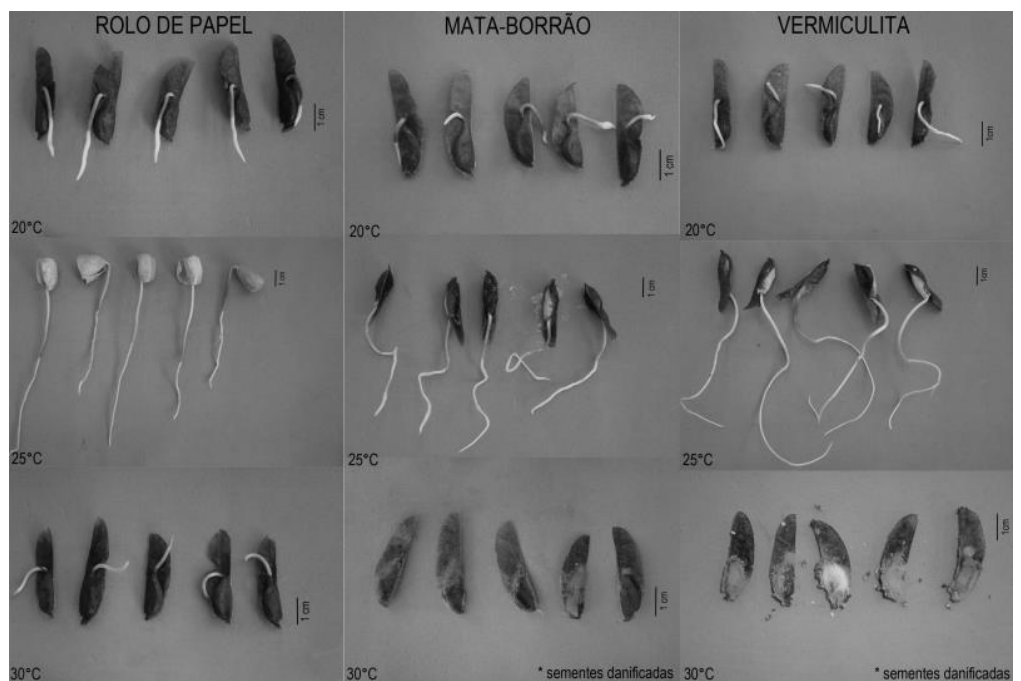

Figura 1. Avaliação final do teste de germinação de sementes de Vochysia bifalcata submetidas a temperaturas constantes de 20,25 e $30{ }^{\circ} \mathrm{C}$ em diferentes substratos aos 20 dias após a semeadura, coletadas em Antonina, PR, 2011.

Figure 1. Final evaluation of Vochysia bifalcata seeds germination test submitted to constant temperatures of 20,25 and $30{ }^{\circ} \mathrm{C}$ with different substrates at 20 days after sowing, collected in Antonina, PR, 2011.

Com relação ao índice de velocidade de germinação (IVG), em todos os substratos estudados os valores mais elevados foram obtidos na temperatura de $25{ }^{\circ} \mathrm{C}$, diferindo significativamente das demais temperaturas (Tabela 2). Assim como para a germinação $\left(25^{\circ} \mathrm{C}\right)$, os substratos papel mata-borrão e vermiculita foram os mais satisfatórios, havendo diferenças significativas apenas entre mata-borrão e rolo de papel.

$\mathrm{Na}$ temperatura de $25^{\circ} \mathrm{C}$, os maiores índices de velocidade de germinação e porcentagens de germinação descritas provavelmente devem-se à melhor uniformidade de umedecimento dos substratos mata-borrão e vermiculita, pois, de acordo com Marcos Filho et al. (1987), é primordial a uniformidade de umidade do substrato durante a condução do teste de germinação. De acordo com Carvalho e Nakagawa (1988), temperaturas inferiores ou superiores à temperatura ótima para germinação tendem a reduzir a velocidade do processo germinativo, expondo as sementes por maior período a fatores adversos, o que resulta na redução da germinação. Esse fato foi observado no presente trabalho, no qual, nas temperaturas de 20 e $30^{\circ} \mathrm{C}$, ocorreu um declínio do IVG em relação à temperatura de $25^{\circ} \mathrm{C}$.

Para o tempo médio de germinação, não houve diferença significativa entre os substratos testados na temperatura ótima de germinação $\left(25^{\circ} \mathrm{C}\right)$, com valores médios de aproximadamente 7 dias (Tabela 2). O período de germinação das sementes de Vochysia bifalcata estabeleceu-se entre o quarto e $12^{\circ}$ dia após a semeadura, para a temperatura ótima de germinação $25^{\circ} \mathrm{C}$ (Figura 2).

Os menores valores do índice de sincronização que caracteriza uma maior sincronia da germinação foram observados à temperatura de $30{ }^{\circ} \mathrm{C}$ nos substratos papel mata-borrão e vermiculita, diferindo 
significativamente dos demais tratamentos (Tabela 2). Para a temperatura de $25{ }^{\circ} \mathrm{C}$, que apresentou bom desempenho germinativo, ocorreu uma menor sincronia na germinação das sementes, não diferindo da temperatura de $20^{\circ} \mathrm{C}$, assim como da temperatura de $30^{\circ} \mathrm{C}$ no substrato rolo de papel. Pode-se inferir que na temperatura de $30{ }^{\circ} \mathrm{C}$ a amostra de semente foi "acionada" para germinar menos vezes do que na temperatura de $25^{\circ} \mathrm{C}$, promovendo assim a maior sincronia, já que uma única semente germinada em um dia pode afetar a sincronia de germinação em toda uma amostra (SANTANA; RANAL, 2000).

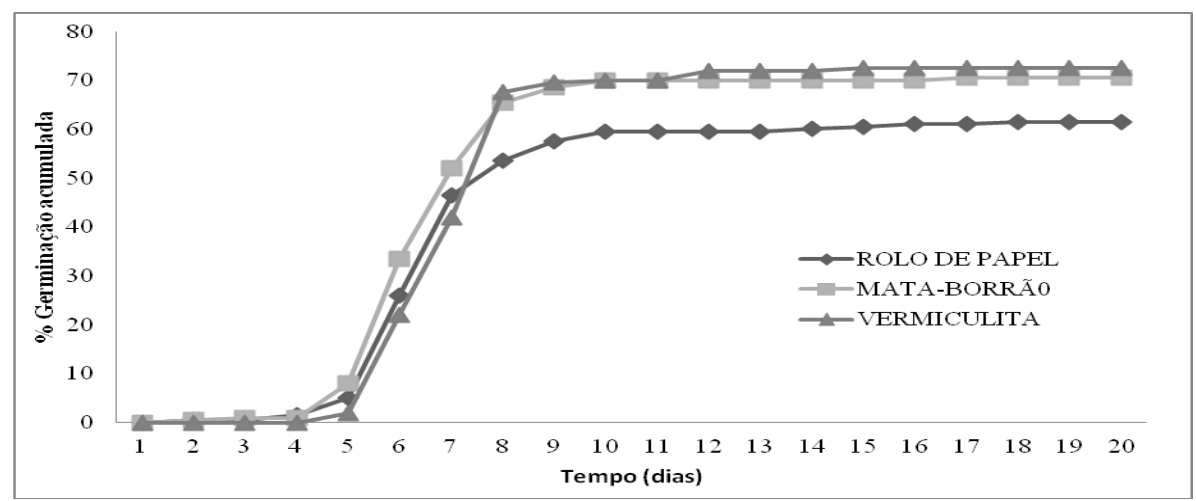

Figura 2. Porcentagem de germinação acumulada de sementes de Vochysia bifalcata à temperatura de $25{ }^{\circ} \mathrm{C}$ em diferentes substratos, coletadas em Antonina, PR, 2011.

Figure 2. Percentage of Vochysia bifalcata seeds cumulative germination at $25{ }^{\circ} \mathrm{C}$ temperature under different substrates, collected in Antonina, PR, 2011.

Com relação à temperatura de $25^{\circ} \mathrm{C}$, a diminuição do tempo e o consequente aumento da velocidade de germinação das sementes de Vochysia bifalcata conferem algumas vantagens. Segundo Rego (2009), quanto mais rápida for a germinação das sementes, menos tempo elas permanecem sob condições adversas, aumentando assim as possibilidades de estabelecimento das plântulas, o que foi evidenciado na germinação de sementes de Blepharocalyx salicifolius.

Os bons resultados no uso dos substratos mata-borrão e vermiculita na temperatura de $25^{\circ} \mathrm{C}$ também foram evidenciados por Pacheco et al. (2006) na germinação de Myracrodruon urundeuva Fr. All., porém observou-se, como no presente trabalho, uma menor capacidade de retenção de água no substrato mata-borrão, sendo necessária a reposição de água durante a condução do experimento. Segundo as R.A.S. (BRASIL, 2009), deve-se evitar, quando possível, o reumedecimento do substrato, que pode gerar variações entre os resultados do teste.

Já a vermiculita é um substrato de fácil manuseio, leve, inorgânico, com boa capacidade de retenção de água, não necessitando de reumedecimento diário, além de proporcionar ótimos resultados com espécies florestais (FIGLIOLIA et al., 1993; SILVA; AGUIAR, 2004). Devido a esse fato, é um substrato que tem apresentado resultados satisfatórios para a germinação de sementes de espécies florestais, como em Amburana cearensis (Allemão) A.C. Smith (GUEDES et al., 2010), Dimorphandra mollis Benth. (PACHECO et al., 2010), Stryphnodendron adstringens (Mart.) Coville (MARTINS et al., 2008) e Caesalpinia echinata Lam. (MELLO; BARBEDO, 2007).

\section{CONCLUSÕES}

- A espécie Vochysia bifalcata apresenta 10.551 sementes por quilo com grau de umidade das sementes de $11,8 \%$.

- Para testes de germinação em laboratório da espécie, recomenda-se o uso dos substratos papel mataborrão ou vermiculita à temperatura constante de $25^{\circ} \mathrm{C}$.

\section{REFERÊNCIAS}

ANDRADE, A. C. S. de; SOUZA, A. F.; RAMOS, F. N.; PEREIRA, T. S.; CRUZ, A. P. M. Germinação de sementes de jenipapo: temperatura, substrato e morfologia do desenvolvimento pós-seminal. Pesquisa Agropecuária Brasileira, Brasília, v. 35, n. 3, p. 609 - 615, 2000. 
BARBOSA, A. R.; YAMAMOTO, K.; VALIO, I. F. M. Effect of light and temperature on germination and early growth of Vochysia tucanorum Mart., Vochysiaceae, in cerrado and forest soil under different radiation levels. Revista Brasileira de Botânica, São Paulo, v. 22, n. 2, p. 275 - 280, 1999.

BORGES, K. C. de F.; SANTANA, D. G. de; RANAL, M.; DORNELES, M. C.; CARVALHO, M. P. Germinação de sementes e emergência de plântulas de Luehea divaricata Mart. Revista Brasileira de Biociências, Porto Alegre, v. 5, n. 2, p. 1008 - 1010, 2007.

BRASIL. Ministério da Agricultura, Pecuária e Abastecimento. Secretaria de Defesa Agropecuária. Regras para análise de sementes. Brasília: MAPA/ACS, 2009. 399 p.

CARPANEZZI, A. A.; CARPANEZZI, O. T. B. Espécies nativas recomendadas para a recuperação ambiental no estado do Paraná, em solos não degradados. Documentos 136. Colombo - PR. Embrapa Florestas, 2006. Disponível em: 〈http://www.cnpf.embrapa.br/publica/seriedoc/edicoes/doc136.pdf〉. Acesso em: 29/09/2010.

CARVALHO, N. M.; NAKAGAWA, J. Sementes: ciência, tecnologia e produção. 3. ed. Campinas: FUNEP, 1988. 424 p.

CARVALHO, P. E. R. Espécies arbóreas brasileiras. v. 1. Brasília: Embrapa Informação Tecnológica; Embrapa Florestas, Colombo, 2003. p. 511 - 516.

FIGLIOLIA, M. B.; OLIVEIRA, E. de C.; PIÑA-RODRIGUES, F. C. M. Análise de sementes In: AGUIAR, I. B. de; PIÑA-RODRIGUES, F. C. M.; FIGLIOLIA, M. B. Sementes florestais tropicais. Brasília, DF: Abrates, 1993. p. 137 - 174.

GUEDES, R. S.; ALVES, E. U.; GONÇALVES, E. P.; BRAGA JÚNIOR, J. M.; VIANA, J. S.; COLARES, P. N. Q. Substratos e temperaturas para testes de germinação e vigor de sementes de Amburana cearensis (Allemão) A. C. Smith. Revista Árvore, Viçosa, v. 34, n. 1, p. 57 - 64, 2010.

LABOURIAU, L. G. A germinação das sementes. Washington: Secretaria Geral da Organização dos Estados Americanos, 1983. 174 p.

LABOURIAU, L. G.; AGUDO, M. On the physiology of germination in Salvia hispanica L. temperature effects. Anais da Academia Brasileira de Ciências, Rio de Janeiro, v. 59, n. 1, p. 37 - 56, 1987.

LORENZI, H. Árvores brasileiras: manual de identificação e cultivo de plantas arbóreas nativas do Brasil. Nova Odessa: Instituto Plantarum, v. 2, 1998. p. 346.

MAGUIRE, J. D. Speed of germination aid in selection and evaluation for seedling emergence and vigor. Crop Science, Madison, v. 2, n. 1, p. 176 - 177, 1962.

MARCOS FILHO, J.; CÍCERO, S. M.; SILVA, W. R. Avaliação da qualidade das sementes. Piracicaba: FEALQ, 1987. 230 p.

MARTINS, C. C.; MACHADO, C. G.; NAKAGAWA, J. Temperatura e substrato para o teste de germinação de sementes de barbatimão (Stryphnodendron adstringens (Mart.) Coville (Leguminosae)). Revista Árvore, Viçosa, v. 32, n. 4, p. 633 - 639, 2008.

MELLO, J. I. de O.; BARBEDO, C. J. Temperatura, luz e substrato para germinação de sementes de paubrasil (Caesalpinia echinata Lam., Leguminosae - Caesalpinioideae). Revista Árvore, Viçosa, v. 31, n. 4, p. $645-655,2007$.

NEGRELLE, R. R. B.; MOROKAWA, R.; RIBAS, C. P. Vochysia Aubl. do estado do Paraná, Brasil. Acta Scientiarum Biological Sciences, Maringá, v. 29, n. 1, p. 29 - 38, 2007.

NOVEMBRE, A. D. da L. C.; FARIA, T. C.; PINTO, D. H. V.; CHAMMA, H. M. C. P. Teste de germinação de sementes de sansão-do-campo (Mimosa caesalpiniaefolia Benth. - Fabaceae Mimosoideae). Revista Brasileira de Sementes, Londrina, v. 29, n. 3, p. 47 - 51, 2007.

PACHECO, M. V.; MATOS, V. P.; FERREIRA, R. L. C.; FELICIANO, A. L. P.; PINTO, K. M. S. Efeito de temperaturas e substratos na germinação de sementes de Myracrodruon urundeuva Fr. All. (Anacardiaceae). Revista Árvore, Viçosa, v. 30, n. 3, p. 359 - 367, 2006. 
PACHECO, M. V.; MATTEI, V. L.; MATOS, V. P.; SENA, L. H. de M. Germination and vigor of Dimorphandra mollis Benth. seeds under different temperatures and substrates. Revista Árvore, Viçosa, v. 34, n. 2, p. 205 - 213, 2010.

REGO, S. S.; NOGUEIRA, A. C.; KUNIYOSHI, Y. S.; SANTOS, A. F. dos. Germinação de sementes de Blepharocalyx salicifolius (H.B.K.) Berg. em diferentes substratos e condições de temperatura, luz e umidade. Revista Brasileira de Sementes, Londrina, v. 31, n. 2, p. 212 - 220, 2009.

RODRIGUES, E. R.; HIRANO, E.; NOGUEIRA, A. C. Germinação de sementes de pessegueiro-bravo sob diferentes condições de luz e substrato. Scientia Agraria, Curitiba, v. 9, n. 1, p. 91 - 94, 2008.

SANTANA, D. G. de; RANAL, M. A. Análise estatística na germinação. Revista Brasileira de Fisiologia Vegetal, Campinas, v. 12 (Edição Especial), p. 205 - 237, 2000.

SILVA, A.; AGUIAR, I. B. de. Germinação de sementes de canela-preta (Ocotea catharinensis Mez Lauraceae) sob condições de luz e temperatura. Revista Instituto Florestal, São Paulo, v. 10, n. 1, p. 17 22, 1998.

SILVA, L. M. de M.; AGUIAR, I. B. de. Efeito dos substratos e temperaturas na germinação de sementes de Cnidosculus phyllacanthus Pax \& K. Hoffm. (faveleira). Revista Brasileira de Sementes, Londrina, v. 26, n. 1, p. 9 - 14, 2004.

Silva, V. P.; COSTA, R. B. da; NOGUEIRA, A. C.; ALBRECHT, J. M. F.; ARAÚJO, A. J. de. Influência da temperatura e luz na germinação de sementes de cambará (Vochysia haenkiana Mart.).

Revista Agricultura Tropical, Cuiabá, v. 4, n. 1, p. 99 - 108, 2000. 